\title{
MUJERES AL FRENTE DEL HOGAR: FAMILIA Y DESIGUALDAD EN EL SUR DE LA INTENDENCIA DE GRANADA A FINES DEL ANTIGUO RÉGIMEN
}

\author{
Daniel Maldonado Cid* \\ Universidad de Castilla-la Mancha
}

\section{RESUMEN}

Los estudios sobre la historia social de las mujeres en un territorio tan extenso como era la Andalucía de finales del Antiguo Régimen aún siguen siendo insuficientes. Partiendo de una sociedad de base paternalista, donde las mujeres quedaron relegadas a un segundo plano, debemos incidir en la visibilidad de este colectivo. Para ello, este trabajo pretende sumarse en esta dirección abordando el análisis de las jefaturas de hogares femeninas, de qué forma participaron estas mujeres en el plano económico y cuál fue el rol que desempeñaron en el sistema social. Los objetivos principales de este trabajo consisten en analizar la tipología de los hogares con jefaturas femeninas, así como conocer en qué medida estas mujeres vivían con mayor o menor frecuencia dentro de un contexto de pobreza, soledad y desigualdad, o de lo contrario, se procuraban una serie de estrategias propias para la supervivencia como el cuidado y elementos de dependencia.

PALABRAS CLAVE: Andalucía, mujeres, familia, trabajo, Antiguo Régimen

Enviado: $3-12-2019$

Aceptado: $25-2-2020$

*daniel.maldonado@uclm.es 


\title{
FEMALE-HEADED HOUSEHOLDS: FAMILY AND INEQUALITY IN THE SOUTHEAST OF ANDALUSIA AT THE END OF ANCIENT REGIME
}

\author{
Daniel Maldonado Cid* \\ Universidad de Castilla-la Mancha
}

\begin{abstract}
Although we must highlight the situation of women of the Old Regime -who were overshadowed by a paternalistic-based society-, our knowledge of women on social history in such a vast territory as Andalusia of the late Old Regime are still insufficient. The purpose of the present study was to determine the role of female-headed households played in the economic and social system. Accordingly, we analyse the structure and composition of households in western Andalusia of the late Old Regime. Additionally, we shed light on how often these women lived within a context of poverty, loneliness and inequality or, otherwise, they sought to provide several different survival strategies such as care and dependency relationships.
\end{abstract}

KEYWORDS: Andalusia, women, family, work, Old Regime

Enviado: 3-12-2019

Aceptado: $25-2-2020$

* daniel.maldonado@uclm.es 


\section{INTRODUCCIÓN}

La reciente historiografía ha dedicado un especial interés a la historia de las mujeres, proporcionándonos un conocimiento mayor sobre el ámbito femenino en el periodo moderno ${ }^{1}$. Las investigaciones han focalizado sus análisis principalmente desde la perspectiva de la familia; $y$, de hecho, fue la historia de la familia la que supuso un punto de apoyo fundamental para integrar la historia de las mujeres en la Historia Social. Desde entonces, se ha ido ampliando el abanico metodológico incluyendo nuevas líneas de investigación como la transmisión del patrimonio por vía femenina, las estrategias matrimoniales, la vejez y la soledad entre otras. Pero, a pesar del impulso que en los últimos años se ha producido al hilo de estos nuevos enfoques de investigación, los estudios sobre la historia de las mujeres en un territorio tan extenso como era la Andalucía de finales del Antiguo Régimen aún siguen siendo insuficientes.

Como sabemos, en otros lugares de la geografía española se ha prestado especial interés al universo femenino en el periodo moderno, prueba de esto lo vemos en algunos trabajos como los de Ofelia Rey Castelao y Serrana Rial García ${ }^{2}$ acerca del trabajo y la vida familiar especialmente en las comunidades marítimas de Galicia ${ }^{3}$. En cuanto al centro-meridional peninsular, destaca el estudio realizado por Francisco García González que aborda cuestiones sobre vejez, jefaturas femeninas y composición de los hogares en localidades próximas a la ciudad de Albacete ${ }^{4}$. En la zona de Extremadura, M. ${ }^{\mathrm{a}}$ Ángeles Bermejo ha trabajado sobre la composición y tamaño de los hogares encabezados por viudas ${ }^{5}$. Sobre jefaturas femeninas en el mundo rural leonés encontramos estudios de la mano de M. ${ }^{a}$ José

1. Este trabajo forma parte del proyecto de investigación Familias, trayectorias y desigualdades sociales en la España centro-meridional, 1700-1930 [Referencia HAR201784226-C6-2-P], dirigido por Francisco García González y Jesús Manuel González Beltrán y que ha sido posible gracias a la financiación concedida por el Ministerio de Economía y Competitividad. A su vez, ha sido financiado mediante la concesión de un contrato para la Formación de Profesorado Universitario (FPU) por el Ministerio de Educación y Formación Profesional.

2. S. M. Rial García (2001); O. Rey Castelao (2006) y a la hora de conocer la producción sobre la historia de las mujeres en Galicia, véase O. Rey Castelao (2009).

3. S. M. Rial García (2005).

4. Dicho estudio muestra cómo, por ejemplo, en el pueblo de El Bonillo, los estados de viudez y soltería no eran incompatibles al proceso de movilidad. F. García GonzÁLEZ (2015). En torno a jefaturas femeninas y soledad, véase F. García GonZÁlez (2017).

5. M. Á. Hernández Bermejo (2012). 
Pérez Álvarez ${ }^{6}$. En Burgos, Francisco José Sanz de la Higuera explora el ámbito doméstico de hogares abandonados por el padre de familia ${ }^{7}$. Asimismo, para Navarra, Amaia Nausía Pimoulier aborda la reconstrucción de las vidas de mujeres desde que enviudan hasta que fallecen ${ }^{8}$.

Si examinamos el balance de la historiografía andaluza, una de las obras de referencia que marcó la ruta a seguir en torno al estudio de la familia y el hogar fue llevada a cabo por James Casey y Bernard Vincent, titulada "Casa y familia en la Granada del Antiguo Régimen", donde se hacía hincapié en la relación de los hogares y el marco socio-profesional de la ciudad de Granada. En esta obra ya se ponía de manifiesto la falta de información derivada del Catastro de Ensenada acerca de la profesión de las mujeres viudas. En este mismo escenario, debemos subrayar algunos trabajos destacados de la esfera femenina, como el de M. ${ }^{a}$ Paz del Cerro Bohórquez centrado en la transmisión del patrimonio en zonas rurales de Cádiz; también el análisis realizado por Martín Miguel Gómez, ajustando su interés en los bienes dotados por las mujeres en el matrimonio en una localidad al norte de la Vega de Granada; así como el trabajo de Isabel Rodríguez Alemán acerca de las segundas nupcias de las viudas de Málaga durante el siglo XVI y el XVII ${ }^{10}$.

Por supuesto, en lo que respecta a trabajos sobre mujeres al frente del hogar, en el entorno andaluz quedan patentes algunos, como los de Margarita Birriel Salcedo ${ }^{11}$ que ha enfocado sus estudios en el territorio granadino y, en los últimos años, ha profundizado sobre la relación de género y espacio doméstico. Al mismo tiempo, es reseñable el reciente análisis sobre jefaturas

6. M. ${ }^{a}$ J. Pérez Álvarez (2013).

7. F. J. SAnZ de la Higuera (2006).

8. A. Nausía Pimoulier (2011).

9. J. CASEy y B. Vincent (1987).

10. En Cádiz venía observándose una predilección por los temas de mujeres, herencia y matrimonio en las zonas rurales de poblaciones como Alcalá de los Gazules, Chiclana

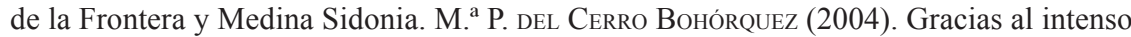
trabajo en demografía histórica y al avance en el análisis de estructuras y tipologías del hogar, se dio paso al interés por los sistemas de herencia y a la importancia del matrimonio. Por este camino se desarrollaron trabajos a nivel local sobre la población de Alfacar. Véase M. Gómez Martín (1997). Isabel Rodríguez Alemán plantea un estudio en el que se observa cómo las fluctuaciones de inmigrantes incidían en el aumento del número de viudas que contraían un nuevo matrimonio. M. ${ }^{a}$ I. Rodriguez Aleman (2008).

11. Para el análisis de los hogares con jefaturas femeninas en la ciudad de Granada, véase M. M. ${ }^{a}$ BirRiel SAlCEdo (2005); y para hogares con jefatura femenina de nueve localidades del Valle de Lecrín, M. M. ${ }^{a}$ Birriel Salcedo (2019). 
femeninas en el Albaicín de Granada, realizado por Sara Cruz Cárdenas ${ }^{12}$. En el caso de Jaén, Raquel Tovar Pulido ${ }^{13}$ pone de manifiesto la poca visibilidad de las profesiones llevadas a cabo por las viudas de la localidad de Vilches y cómo algunas realidades sociales basadas en la desigualdad, como la marginalidad y la pobreza, incidían en la vida de estas mujeres.

Además, en los análisis que ha llevado a cabo María José de la Pascua Sánchez en la ciudad de Cádiz, podemos considerar la historia de la familia desde el punto de vista de la conflictividad; en palabras de la autora como "una familia constituida sobre relaciones de poder, de desigualdad entre los sexos y, por consiguiente, como ámbito de conflicto"14. Esta autora concreta aún más sobre la importancia de los estudios relacionados con la pobreza y la asistencia social en otro de sus trabajos, titulado: "A la sombra de hombres ausentes: mujeres malcasadas en el mundo hispánico del setecientos", donde hace referencia al seguimiento de los relatos de vida y el uso de herramientas cualitativas que mejoren nuestra perspectiva del pasado rompiendo la visión (en palabras de la autora), "victimista" de las mujeres en el Antiguo Régimen ${ }^{15}$.

Finalmente debemos destacar dos trabajos publicados en el último monográfico número 45 de la revista Chronica Nova (2019). El primero, elaborado por Francisco Sánchez-Montes González, lleva por nombre "La familia en el reino de Granada en la Edad Moderna" que subraya el aumento de investigaciones sobre la historia de la familia en territorio andaluz en los últimos años y nos recuerda la suma importancia del cruce de diferentes fuentes de documentación para aumentar el carácter cualitativo de los estudios ${ }^{16}$. El segundo, realizado por Francisco García González y Daniel Maldonado Cid, insiste en la falta de estudios que contemplen en sus análisis la estructura, el tamaño y la composición de los hogares, a la vez que ofrece una aproximación a los datos aportados por otras publicaciones que permiten la comparación entre distintas regiones ${ }^{17}$. A la vista queda presente, pues, que el sureste peninsular, fundamentalmente en las zonas costeras del antiguo reino de Granada adolece de un vacío bibliográfico en lo que a jefaturas femeninas se refiere.

A la hora de llevar a cabo este trabajo, los objetivos principales se centran en analizar la tipología familiar de los hogares encabezados por

12. S. CRuz CÁrdenas (2019).

13. R. Tovar Pulido (2014-2015).

14. M. a J. de la Pascua Sánchez (2016a), 153.

15. Es remarcable el número de mujeres casadas al frente del hogar y con marido ausente. M. ${ }^{a}$ J. de la Pascua Sánchez (2016b), 275.

16. F. SÁnchez-Montes González (2019).

17. F. García González y D. Maldonado Cid (2019). 
mujeres, ya que ello nos permitirá después saber hasta qué punto incide su papel en el entramado social de su comunidad. También necesitamos conocer si la vida de estas mujeres estaba ligada a la pobreza de forma considerable o, si de lo contrario, se procuraban una serie de estrategias propias para la supervivencia, como el cuidado y elementos de dependencia que las alejaban del desamparo y la soledad. En este sentido, se hace imprescindible explorar los niveles de propiedad y riqueza a los que podían acceder estas jefas del hogar.

En cuanto a la coordenada espacial, se trata de un territorio que comprende la Alpujarra baja y parte de la actual costa granadina o también conocida como Costa Tropical. Esta zona, a finales del Antiguo Régimen, según el vecindario de Ensenada ${ }^{18}$, se encontraba repartida administrativamente en una serie de partidos pertenecientes a la intendencia o provincia de Granada ${ }^{19}$. En concreto se ha utilizado una muestra de poblaciones que cuenta con 3161 hogares seculares y un total de 11504 habitantes. Dichos núcleos de población son los siguientes: Motril ${ }^{20}$, donde prácticamente la actividad económica azucarera copó la gran mayoría de la centuria ilustrada ${ }^{21}$, un hecho que ya venía apreciándose a lo largo del siglo XVII, lo cual impulsó un rápido crecimiento demográfico. Lo mismo ocurría a fines del Antiguo Régimen en Almuñécar ${ }^{22}$, donde la agricultura fue la base económica principal hasta bien entrado el siglo XIX. A comienzos de la modernidad, ambos núcleos de población formaban parte de la red de puertos repartidos por toda la costa del reino de Granada llegando a ser denominados como "puertos del azúcar"23. De igual modo, los núcleos de población: Lújar, Rubite y Albuñol (este último llegaría a ser cabeza de partido con la reforma territorial de 1834), situados en una zona, sobre las antiguas tahas de Cueyhel (a la que pertenecen Rubite y Lújar), en la vertiente

18. El Vecindario de Ensenada fue conformado en 1759 y es una fuente de especial valor, puesto que es complementario de los libros de familia y propiedad del propio Catastro de Ensenada. Véase C. Camarero Bullón, A. Aguilar Cuesta y L. García Juan (2018).

19. La intendencia de Granada agrupaba las actuales provincias de Granada, Málaga y Almería. Las entidades poblacionales analizadas en este trabajo pertenecen a los siguientes partidos judiciales: partido de Almuñécar, partido de Motril, partido de Torvizcón (contempla las localidades de Albuñol, Rubite y Lújar, utilizadas en esta muestra).

20. Para conocer más sobre esta población, véase P. A. Porras Arboledas (2006).

21. J. L. Castellano (2012).

22. Para ampliar información sobre la evolución demográfica de Almunécar en el siglo XVIII, véase M. ${ }^{a}$ A. Fernández García (1982).

23. R. M. Girón Pascual (2015), 14. 
meridional de la sierra de Lújar, y de Cehel, enclavada en la sierra de la Contraviesa, cuya cabeza administrativa había sido la entidad de Albuñol, que según el Catastro de Ensenada mantenía bajo su jurisdicción el castillo de la Rábita ${ }^{24}$. De hecho, esta zona hubo de soportar de manera frecuente el acoso de la piratería berberisca. A medida que avanza la segunda mitad del siglo XVIII, Albuñol crecerá en densidad de población ${ }^{25}$ y la Sierra de Lújar seguía siendo un referente en la explotación minera de la zona ${ }^{26}$.

Son varios los factores que han llevado a elegir estas entidades de población. Por un lado, se ha tenido en cuenta el buen estado de la fuente de documentación. Por otro lado, hay que acentuar su valor y riqueza documental, de forma particular en las relaciones juradas de Albuñol, donde se hallan conexiones entre las distintas localidades, a través de vecinos de Motril y Rubite que declaran propiedades en Albuñol.

\section{Mapa 1. Localización de las entidades de población elegidas en la muestra}

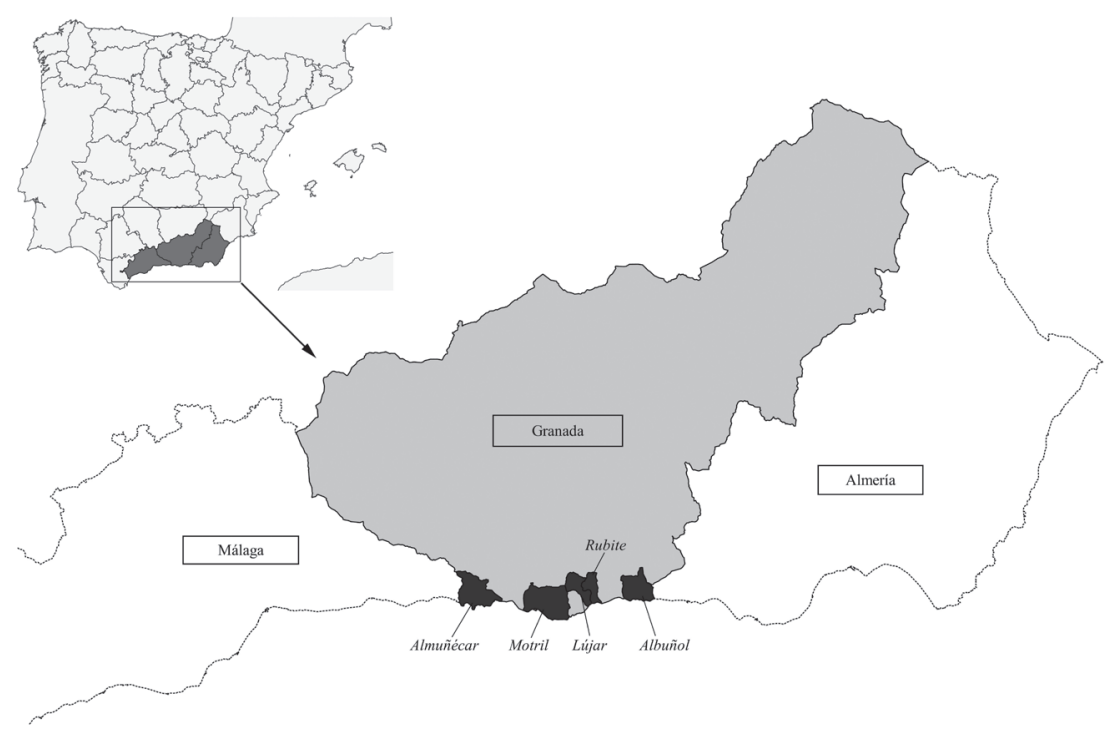

Fuente: Elaboración propia.

24. Para obtener un conocimiento mayor sobre la configuración del partido de Torvizcón, véase M. ${ }^{\mathrm{a}}$ A. Fernández García (1985), 124-126.

25. "Albuñol (...) Pasa éste de $26 \mathrm{H} / \mathrm{Km}^{2}$ en 1752 a $34 \mathrm{H} / \mathrm{Km}^{2}$ en 1768 alcanzando en 17861 os $34 \mathrm{H} / \mathrm{Km}^{2}$ ". M. ${ }^{\mathrm{a}}$ A. Fernández García (1985), 131.

26. M. A. Sorroche (2014), 306. 
La metodología de trabajo llevada a cabo utiliza, en primer lugar, la tipología de Peter Laslett que nos permite establecer una aproximación inicial al conocimiento de la estructura de los hogares y que asienta la base para los análisis posteriores. De este modo, ha sido consultada la documentación de Hacienda del Catastro de Ensenada, concretamente los libros del vecindario secular, prescindiendo de los vecindarios eclesiásticos. En segundo lugar, para los casos de las localidades costeras de Albuñol y Motril, hemos revisado los legajos referentes a las relaciones juradas donde toma especial valor la información relativa a las rentas y la propiedad de los vecinos. En este sentido, se ha tomado un tamaño de muestra significativo para Albuñol, tanto de hombres como de mujeres. En el caso de Motril se han tomado ejemplos representativos que nos ayudan a comparar ambas localidades. Por último, se han revisado los protocolos notariales de la villa de Albuñol correspondientes a los años comprendidos entre 1749 y 1760 procedentes del Archivo de Protocolos del Colegio Notarial de Granada ${ }^{27}$. Por lo que a través de la comparación de dichas fuentes podremos situar la vida de estas mujeres en el entramado social.

\section{LIDERAZGO DE LOS HOGARES: HOMBRES Y MUJERES AL FRENTE}

Teniendo en cuenta las cifras de la muestra total de poblaciones y observando los datos reflejados en la Tabla 1, del cómputo total de hogares analizados, el $18,5 \%$ están liderados por mujeres ${ }^{28}$. A priori, esta cifra no parece tener un peso de especial relevancia, considerando que, entre ambos sexos, el mayor número de jefaturas las protagonizan los hombres con un $81,49 \%$. Sin embargo, es sumamente crucial no mantener una mirada

27. Con más detalle, la documentación consultada ha sido: Catastro de Ensenada. Documentación de Hacienda. Respuestas particulares de Albuñol. Archivo Histórico Provincial de Granada (AHPGr), lib. 964 y 965. Respuestas particulares de Rubite. AHPGr, lib. 1534. Respuestas particulares de Lújar. AHPGr, lib. 1371. Respuestas particulares de Almuñécar. AHPGr, lib. 1012. Respuestas particulares de Motril. AHPGr, lib. 1425 y 1429. Con respecto a la documentación notarial, se han trabajado los libros: Protocolos Notariales. Escribanía de Benito García Calleja, leg. AB-41; AB-42; AB-43, del Archivo de Protocolos del Colegio Notarial de Granada (APGr).

28. Datos que coinciden con los extraídos en la población de Alhaurín el Grande, donde el porcentaje de mujeres cabezas de familia también es de un $18,5 \%$. J. RuEda Solano (2013), 193. 
sesgada de la historia ${ }^{29}$ por lo que debemos resaltar las peculiaridades de estas jefaturas femeninas. En cualquier caso, es un dato muy similar a los expresados por Birriel Salcedo en el Valle de Lecrín con un 18,6 \% ${ }^{30}$. Asimismo, expresa un porcentaje muy cercano a los procedentes de la España centro-meridional que proyectan un $17,1 \%{ }^{31}$, y no muy lejana del porcentaje obtenido de Francia en la primera mitad del siglo XIX con un $18,1 \%^{32}$. Por lo tanto, más allá del mayor o menor valor porcentual, se advierte cierta similitud con otras regiones geográficas. En algunos casos, se dan diferencias de jefaturas femeninas entre localidades; de hecho, en nuestra muestra pueden apreciarse en los seis puntos porcentuales que separan Rubite, con un 15,63 \%, de Motril y Albuñol que rondan el $21 \%$ aproximadamente. Aun así, dichas diferencias no radican en el número de vecinos, el número de habitantes, ni en absoluto en la orografía, por lo que debemos prestar atención a otros factores como el estado civil, el tamaño y la tipología del hogar, o la edad.

Tabla 1. Hogares encabezados por hombres y mujeres en una muestra de poblaciones en el sur de la Intendencia de Granada (1752)

\begin{tabular}{|lccc|cccc|}
\hline Población & $\begin{array}{c}\text { N. } \text { }^{\text {total de }} \\
\text { hogares }\end{array}$ & Hombres & Mujeres & Viudas & Solteras & $\begin{array}{c}\text { Con } \\
\text { marido } \\
\text { ausente }\end{array}$ & Desc. \\
\hline Motril & 1985 & 78,74 & 21,26 & 87,91 & 10,66 & 0,47 & 0,95 \\
Almuñécar & 640 & 82,03 & 17,97 & 92,17 & 5,22 & - & 2,61 \\
Albuñol & 369 & 78,59 & 21,41 & 84,81 & 2,53 & 10,12 & 2,53 \\
Lújar & 103 & 81,55 & 18,45 & 94,74 & 5,26 & - & - \\
Rubite & 64 & 84,38 & 15,63 & 100,00 & - & - & - \\
\hline Total & $\mathbf{3 1 6 1}$ & $\mathbf{8 1 , 4 9}$ & $\mathbf{1 8 , 5 0}$ & $\mathbf{8 8 , 7 5}$ & $\mathbf{7 , 1 8}$ & $\mathbf{1 , 7 0}$ & $\mathbf{1 , 3 7}$ \\
\hline
\end{tabular}

Nota: Salvo el número total de hogares, el resto de las cifras están expresadas en porcentajes. Fuente: Libros de los Vecindarios Seculares del Catastro de Ensenada. Véase la nota 27. Elaboración propia.

29. S. M. Rial García (2005), 15.

30. M. ${ }^{a}$ Birriel Salcedo (2019), 61.

31. F. García González (2017), 29.

32. R. Gehrmann (2017), 174.

(C) Baetica. Estudios Historia Moderna y Contemporánea, 39, 2019, 189-218. Facultad de Filosofia y Letras, Universidad de Málaga. Departamento de Historia Moderna y Contemporánea 


\subsection{Estado civil: mujeres solteras, viudas y con marido ausente}

Es cierto que la información procesada no mantiene una correlación entre las variables mencionadas. Entonces, ¿a qué se debe esta disimilitud? Puede que, prestando atención al estado civil, veamos cómo varían de manera notable las cifras según el núcleo de población. Como podemos apreciar, la inmensa mayoría de los hogares encabezados por mujeres están caracterizados por el estado de viudez, como por ejemplo la localidad de Rubite, donde todas las mujeres cabeza de familia son viudas, y el resto de los casos superan el $84 \%$, algo parecido a los datos arrojados para la localidad jienense de Vilches con un $82,41 \%{ }^{33}$. Esta cifra es claramente llamativa frente al porcentaje de mujeres solteras y de mujeres con el marido ausente, donde el máximo apenas supera la décima parte.

Al comparar entre hombres y mujeres, las diferencias confirman el mayor peso de los hogares encabezados por viudas frente a viudos. Por citar un ejemplo, en Albuñol los viudos al frente de sus hogares comprendían un 7,24 \%, y en el caso de las viudas que lideran su casa son un $84,81 \%$. Las dificultades de volver a contraer matrimonio no afectaban de igual modo a ambos sexos. El porcentaje de varones que fallecían tendía a ser más elevado que el de mujeres y la capacidad de volver a contraer nupcias era mayor en los hombres ${ }^{34}$. El mercado matrimonial para ellos parece ser que tenía menos complicaciones para una nueva unión. Igualmente, que hubiera mayor índice de viudez femenina puede estar unido a una mayor longevidad ${ }^{35}$.

En cuanto a la soltería, estas mujeres suman el 7,18\% de los hogares encabezados por ellas. Un valor semejante al del Valle de Lecrín, con un $8,33 \%{ }^{36}$, y ligeramente inferior al reflejado en la España centro-meridional, que alcanza el 8,9\% $\%^{37}$. Aquí las diferencias entre ambos sexos vuelven a ser reseñables. El porcentaje de solteras en la localidad de Lújar sumaba hasta un 10,66\% del total de los hogares liderados por mujeres. En cambio, del total de hogares encabezados por hombres, apenas un 2,60 $\%$ eran solteros. A pesar de esto, hallamos matices entre las distintas localidades. El núcleo de población con el valor más alto es Motril, con

33. R. Tovar Pulido (2014-2015), 409.

34. Para ver datos sobre las segundas nupcias en Granada, véase J. Sanz Sampelayo (1978).

35. A. Nausia Pimoulier (2006), 238-239.

36. M. M. ${ }^{a}$ Birriel Salcedo (2019), 72.

37. F. García González (2015), 147. 
un porcentaje por encima del $10 \%$. Aquí, la mitad de las mujeres solteras al frente del hogar tenían otorgado el estatus de “doña”. En Almuñécar, sin embargo, la categorización del estado de soltería se convierte en una tarea más difícil de contemplar, ya que son numerosos los casos de jefaturas femeninas que no advierten su estado civil, y, aunque la edad y la configuración del hogar pueden darnos pistas, no podemos confirmarlo exactamente. Por ejemplo, en la población de Motril estas mujeres solían ostentar el nombre, en algunos casos, de soltera o en otros casos el de doncella. Y en Albuñol solo existía la descripción de "doncella". Aunque este aspecto no lo desarrollamos con mayor detenimiento en este trabajo, viene a indicarnos la pluralidad y diversidad de las designaciones que se hicieron a la hora de listar los vecindarios del Catastro de Ensenada.

Por último, y de forma singular, Albuñol alberga el mayor número de mujeres con marido ausente llegando al 10,12 \%. Aunque nuestra muestra revela un porcentaje de hogares con el esposo ausente que a primera vista no es llamativo, no debemos ignorar a este grupo de mujeres, abandonadas temporal o definitivamente ${ }^{38}$, que se encontraban a medio camino entre la viudez y el matrimonio. Estamos ante una realidad difícil de abordar, nuevamente a causa del tratamiento que la fuente hizo en el momento de recopilación de información. La falta de datos se convierte en un verdadero problema. Lo habitual en estas circunstancias es que el marido haya abandonado el hogar por propia voluntad o por haber fallecido sin que se tuviera noticia de ello. A diferencia de otros núcleos de población, en la localidad de Albuñol, el nombre del marido desaparecido sí aparece descrito en la gran mayoría de los hogares liderados por una mujer casada, así como la posible causa de su paradero. El motivo solía ser "ausencia por estar matriculados en los navíos", como era el caso de Paula Martín, de 48 años, cuyo marido, de nombre Bartolomé Rodríguez, se encontraba ausente y estaba matriculado en los navíos. Paula llevaba el cuidado de la casa y de sus tres hijos, Lucas, María y Manuel, de 7, 4 y 3 años, respectivamente ${ }^{39}$.

38. Muchas de estas mujeres que legalmente están casadas, en el momento de ser abandonadas desconocían cuál era su estado civil. Para ver datos pertenecientes a Burgos a mitad del siglo XVIII, véase F. J. SAnZ de La Higuera (2006), 214-215.

39. AHPGr, Catastro de Ensenada, lib. 964, fol. 80v. 


\subsection{La dimensión y estructura de los hogares encabezados por mujeres}

Otro factor clave es el tamaño de los hogares. Contabilizando el total de habitantes (incluyendo el número de criados) de las cinco localidades de esta muestra, en 1752 el tamaño medio de los hogares da un valor de 3,63 individuos. Dicho coeficiente se ajusta a los indicados en otras poblaciones de la Intendencia granadina y de la Andalucía moderna ${ }^{40}$. Claramente, no suponen hogares donde cohabita un gran número de familiares, sino todo lo contrario. Por ejemplo, en Almuñécar el tamaño era todavía más bajo, de 3,54, un índice que no va mucho más allá de los tres individuos por hogar. No obstante, los datos encajan con el modelo de la España rural centro-meridional donde era algo superior obteniendo hasta los 3,94. En cualquier caso, coincidimos en nuestra aportación con lo que ya indicaba Francisco García González sobre la visión estereotipada que podemos hacernos acerca de la familia en el Antiguo Régimen, donde los hogares tienden a ser de tamaño reducido, frente a la idea hogares complejos donde conviven numerosos hijos y parientes $^{41}$.

De otro lado, los hogares liderados por mujeres en esta muestra de poblaciones tienen un tamaño medio de 3,08 personas por hogar. Supone una cifra afín a los datos reflejados por Birriel Salcedo en el Valle de Lecrín ${ }^{42}$, el cual es de 2,9 y algo superior a la zona de León ${ }^{43}$, donde no superan el 2,7. De nuevo, las diferencias entre localidades no responden a una dinámica o factor concreto. Por un lado, Motril y Almuñécar albergan un 2,98 y 2,96 respectivamente. Por otro lado, Rubite $(4,30)$, Albuñol $(3,48)$ y Lújar $(3,36)$ expresan promedios algo más altos. En este contexto debemos señalar la importancia de los hijos en los hogares con jefatura femenina, puesto que en estas cinco localidades suman hasta un 56,21\% del total de integrantes. En ningún caso esto significa que el nivel reproductivo fuese prolífico. El número de hijos que comprendían los hogares encabezados por mujeres en Albuñol constituía unos 2,2 descendientes, algo mayor que Motril, con 1,7, o Lújar, contando hasta 1,89 vástagos por vecino. Esta realidad puede

40. Los datos que ofrece una muestra realizada en la Andalucía oriental expresan 3,79 miembros por hogar. F. García González y D. Maldonado Cid (2019), 147-148.

41. F. García González (2011), 189.

42. M. M. ${ }^{a}$ Birriel Salcedo (2019), 63.

43. M. ${ }^{a}$ J. Pérez Álvarez (2013), 25. 
deberse entre otras circunstancias al hecho de que en el sur peninsular tuvo lugar un periodo reproductivo muy largo, pero poco productivo, podía pasar un año y medio o incluso dos años desde la unión matrimonial hasta tener el primer hijo ${ }^{44}$. Algunos de los factores que incidían en esta dinámica eran las condiciones duras de trabajo o los niveles de nutrición escasos e incluso la ruptura de la familia por el fallecimiento de uno de los cónyuges. Es inequívoco que el tamaño era reducido, sin embargo, se daban casos donde evidentemente se llegaba incluso hasta los 8 componentes conviviendo en el mismo hogar. Tal es el caso de Rosalía Pérez ${ }^{45}$, viuda, que a sus 40 años mantiene a sus 6 hijos de entre 3 y 16 años, todos ellos habitantes de Albuñol y conviviendo con Valeriano Ruiz, sin aparente relación familiar, oficial de herrero y de edad 60 años. Además, esta mujer tiene "a cargo y providencia los oficios de herrero y herrador", ya que entre sus bienes posee una fragua por la cual puede sacar hasta 1200 reales de vellón donde con toda seguridad trabaja el propio Valeriano.

Aunque no es habitual hallar hogares tan amplios, nos podemos preguntar ¿cuántos hogares había constituidos únicamente por mujeres? A primera vista, el volumen de hogares habitados solo por mujeres $(7,46 \%$ del total de hogares de la muestra) parece no indicar ninguna evidencia que respalde la importancia de este conjunto. Sin embargo, con respecto al recuento total de hogares con jefatura femenina, este perfil reúne hasta un 40,34\%. Las implicaciones de esta observación en torno a la dimensión femenina de los hogares radican en el peso de los hogares solitarios. Fijándonos en el Gráfico 1, estos suponen exactamente la mitad de los hogares íntegramente habitados por mujeres, donde, por ejemplo, Almuñécar supera la media alcanzando el 63,83\%.

44. Intentar entender cuáles son concretamente los factores que constituyen la composición del hogar es una ardua tarea y es verdaderamente difícil correlacionar matrimonio precoz y altas tasas de fecundidad ya que la diversidad regional no obedece a ningún patrón determinado. Véase A. Marcos Martín, (2000), 51.

45. AHPGr, Catastro de Ensenada, lib. 964, fol. 70v. 
Gráfico 1. Hogares habitados enteramente por mujeres (1752)

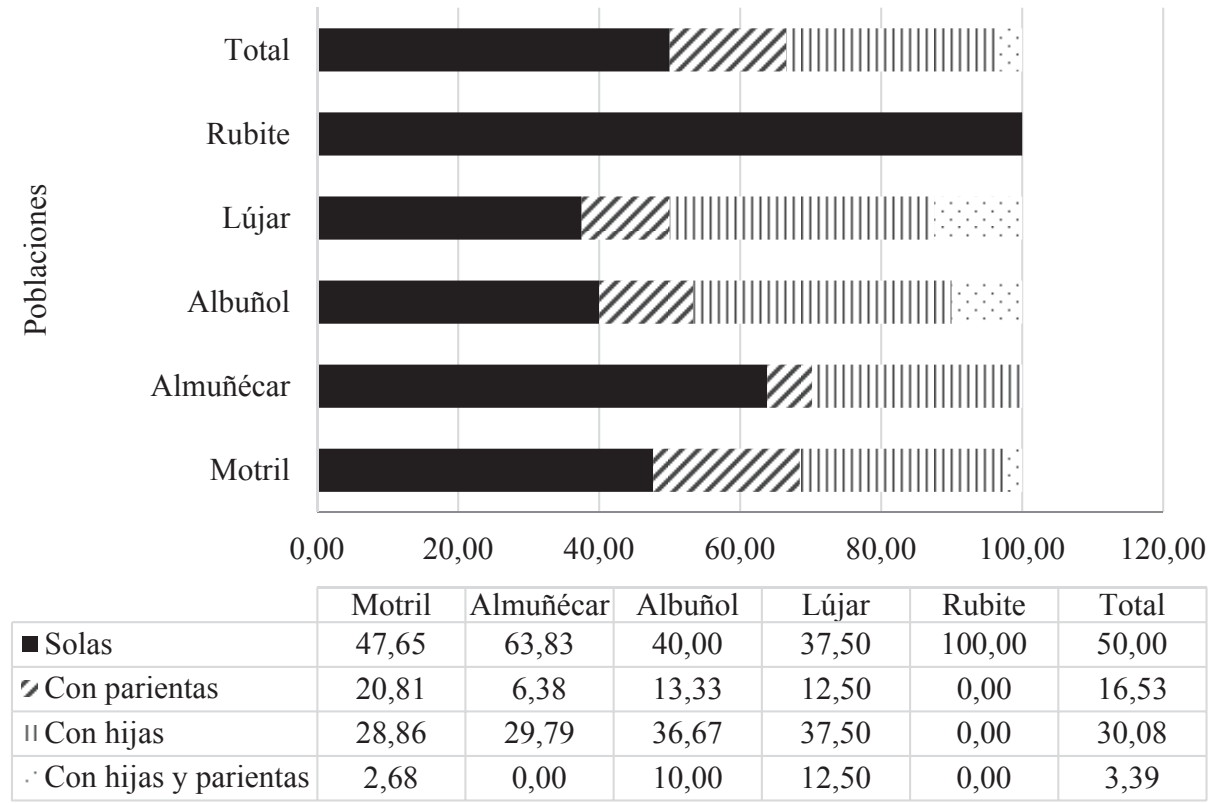

Porcentajes

Fuente: Véase la nota 27. Elaboración propia.

Igualmente, tres de cada diez hogares habitados por mujeres estaban compuestos por madres e hijas. Así es el caso de Antonia Rosales, viuda pobre de 51 años, vecina de Motril, que vive con sus 5 hijas, Tomasa González Castellanos, Casilda, María, Vicenta y Francisca, todas ellas de entre 10 y 27 años $^{46}$. En cuanto a si estas jefas de hogar vivían o no solo con otras parientas, la cifra es algo menor, y a pesar de las diferencias que se aprecian entre algunas poblaciones, como es el caso de Motril con un 20,81 \%, o el de Almuñécar con tan solo un 6,38 \%, no era extraño ver hogares configurados por hermanas o alguna abuela con una nieta.

Volviendo a la muestra total, profundizando aún más en la estructura familiar de los hogares y observando los datos de la Tabla 2, este tipo de espacios compartidos por otros parientes, es decir, hermanos, tíos, sobrinos, y nietos entre otros, no cuenta con valores muy altos en el análisis de la muestra.

46. AHPGr, Catastro de Ensenada, lib. 1425, fol. 58v. 
Aun así, las relaciones familiares eran cruciales para la supervivencia. Unos asistían en la casa de algún familiar o en su lugar, otros eran dependientes, inclusive ambas $\operatorname{cosas}^{47}$. Una situación como esta la vivieron en la localidad de Motril la viuda de 87 años Ana Laredo y sus dos hijos, hijo e hija de 44 y 46 años respectivamente. En propiedad tenía un viñedo con casa de campo y dos casas, una de ellas la usaba su hija Inés Madrigal para guardar toneleras y accesorios. Inés tenía a su vez una hija. A raíz de esto podemos pensar en los cuidados que puede demandar Ana Laredo de su hija, pero también podemos conjeturar que hija y nieta vivían en la casa de la susodicha debido a la posible ausencia del marido o el apoyo indispensable de solidaridad que tanto el hermano como la madre pueden ofrecer a la propia Inés ${ }^{48}$.

En definitiva, los lazos de dependencia entre parientes podían aumentar o disminuir a lo largo de toda una vida. También existían multitud de circunstancias que podían llevar a rupturas y conflictos entre familiares y parientes. Sin embargo, en otros casos, la estrechez de estos vínculos nacía de una cierta obligatoriedad en el cuidado, especialmente el de aquellos que han quedado huérfanos de madre y padre. Tal es el caso de la joven de 16 años Francisca López, huérfana de los dos progenitores, que vivía con su abuela Jacinta López, viuda de 70 años, ambas vecinas de Albuñol ${ }^{49}$. Como ya decíamos, no es raro encontrar abuelos y nietos viviendo juntos. De hecho, la incidencia que pueden tener estos jóvenes en el cuidado de sus mayores puede llegar a ser altamente positiva. En un estudio que se realizó sobre el norte de Suecia en época preindustrial, el número de niños que habitaban los hogares supuso una variable precisa como indicador del nivel de asistencia en la vejez, donde un niño más en el hogar aumentaba esas posibilidades de asistencia ${ }^{50}$.

Pero, como sugeríamos anteriormente, la mayor parte de los hogares encabezados por mujeres responde a un modelo familiar de tipo nuclear dominado principalmente por viudas. En nuestro caso, alcanza el 60,34 \%, algo similar a lo observado en la zona de la costa occidental gallega, en donde llega hasta el $64 \%$ aproximadamente ${ }^{51}$. Asimismo, se caracteriza por ser un modelo mayormente constituido por una madre e hijos. Posiblemente, el repentino fallecimiento del cónyuge detona la rápida responsabilidad que han de ejercer estas féminas. La jefatura implica el dominio

47. E. Velasco Merino (2014), 9.

48. AHPGr, Catastro de Ensenada, lib. 1425, fol. 19r.

49. AHPGr, Catastro de Ensenada, lib. 964, fol. 57v.

50. S. Edvinsson y G. Broström (2012), 642.

51. S. Rial García y O. Rey Castelao (2008), 94. 
de las responsabilidades (economía y sustento del hogar; cuidado de los hijos o el cargo de un oficio entre otros), justo en un momento clave del ciclo familiar, especialmente si se trata de hogares con varios hijos, ya que la carga familiar aumenta de manera considerable. Tarde o temprano, los hijos tendrán la obligación de incorporarse al mercado laboral y las madres, ahora jefas de hogar deberán adaptarse a una nueva situación, que, aun propiciando un cierto halo de independencia, también supone un verdadero reto para la supervivencia.

Tabla 2. La estructura de los hogares encabezados por mujeres en una muestra de poblaciones en el sur de la Intendencia de Granada (1752)

\begin{tabular}{|c|cccccccc|}
\hline Población & Solitario & $\begin{array}{c}\text { Sin } \\
\text { estructura }\end{array}$ & Nuclear & Extenso & Múltiple & Complejo & Hogares & Hab. \\
\hline Motril & 19,9 & 9,1 & 66,3 & 1,7 & 3,0 & 4,7 & 362 & 6869 \\
Almuñécar & 25,2 & 2,6 & 67,8 & 2,6 & 1,7 & 4,3 & 115 & 2282 \\
Albuñol & 15,2 & 6,3 & 69,6 & 2,5 & 6,3 & 8,86 & 79 & 1646 \\
Lújar & 15,8 & 15,8 & 57,89 & 5,26 & 5,26 & 10,5 & 19 & 405 \\
Rubite & 20,0 & - & 70,0 & - & 10,0 & 10,0 & 10 & 302 \\
Total & $\mathbf{1 8 , 2 9}$ & $\mathbf{6 , 8 3}$ & $\mathbf{6 0 , 3 4}$ & $\mathbf{2 , 0}$ & $\mathbf{2 , 9}$ & $\mathbf{4 , 9}$ & $\mathbf{5 8 5}$ & $\mathbf{1 1 5 0 4}$ \\
muestra & & & & & & & &
\end{tabular}

Nota: Las cantidades están expresadas en porcentajes sobre el total de hogares encabezados por mujeres. El número de habitantes expresa el cómputo total de cada localidad. Fuente: Véase la nota 27. Elaboración propia.

En cualquier caso, tanto el tamaño como la estructura familiar no establecen modelos rígidos ni estáticos. Es cierto que nuestro análisis reproduce un momento de mediados del siglo XVIII, pero insinúa una tendencia de dinamismo por el cual las familias integran o pierden miembros ${ }^{52}$. En algunos momentos de este ciclo familiar, los hogares se reducen hasta su mínima expresión, es decir, una única persona como cabeza de familia. En esta muestra, el peso de los hogares de mujeres solas oscila entre un 15 y un $25 \%$, y su estado civil es el de viuda en aproximadamente el $80 \%$. Estas mujeres permanecen en sus viviendas prefiriendo así contar con cierta independencia ${ }^{53}$, como es el caso de Ana Rodríguez ${ }^{54}$, viuda pobre de 60 años,

52. J. Casey y B. Vincent (1987), 185.

53. L. Botelho (2013), 302-303.

54. AHPGr, Catastro de Ensenada, lib. 1429, fol. 1299. 
vecina de Motril que declara tener en propiedad una casa que se compone de un cuarto y un corral, situada en la Rambla de San Roque, lindando por el norte con la casa de Francisca Ruiz, viuda pobre de 54 años ${ }^{55}$. Aunque desafortunadamente no tengamos en nuestras manos más información, no podemos evitar preguntarnos qué tipo de relaciones y vínculos mantendrían estas dos vecinas que se hallan en la cincuentena de edad y viviendo solas donde la separación de sus vidas tan solo es el muro que separa sus viviendas.

\subsection{Edad y ciclo de vida de las mujeres que lideran su casa}

Como hemos comprobado, el estudio de los hogares no puede desligarse en ningún caso del análisis del tipo de familia o el estado civil. Ahora bien, los individuos no son impasibles al paso del tiempo y las características que constituyen la configuración familiar también van cambiando. Por lo tanto, la edad supone una variable trascendental para comprender los comportamientos sociales.

Al observar el Gráfico 2, lo primero que llama nuestra atención es que los intervalos de edad con mayor o menor presencia de las jefas de hogar varían según el estado civil. Inicialmente, comprobamos como es poco probable encontrar mujeres que lideren sus hogares por debajo del umbral de los 20 años. Tanto solteras como mujeres con el marido ausente tienden a ser más jóvenes (entre los 20 y los 29 años) que las que se encuentran en estado de viudez, cuyo rango de edad con un número mayor de mujeres comprende los 50-59 años. Este hecho se verifica al revisar la media de edad de los hombres cabeza de familia, la cual no pasa de los 40 años y, en cambio, la de las mujeres es raro que baje de los 50 años.

Si prestamos atención al ciclo de vida y a la dimensión de los hogares, ocurre que la reducción del tamaño del hogar aumenta en hogares con jefaturas de 65 años y más. A partir de esta edad es menos frecuente la presencia de hogares complejos. Dicha correlación entre la avanzada edad y estos hogares de tamaño reducido nos advierte en cierto modo sobre un aspecto importante. Los hogares encabezados por mujeres que comprenden esta edad en adelante tan solo albergan 2,07 componentes por agregado doméstico. Aunque ya lo anunciábamos anteriormente, el modelo familiar preponderante es el de viuda con hijos; de hecho, los porcentajes al respecto oscilan entre el 60 y el $70 \%{ }^{56}$ del total de hogares con jefatura femenina. Además, en los hogares liderados por mujeres que

55. AHPGr, Catastro de Ensenada, lib. 1425, fol. 86v.

$56 \mathrm{Se}$ trata de datos muy similares a los reflejados en Inglaterra durante la segunda mitad del siglo XVIII. Véase B. Moring y R. Wall (2017), 215. 
dejan tras de sí la etapa de madurez, es bastante normal localizar algún hijo que permanece viviendo con su madre.

Claramente, en estos hogares, unos hijos han abandonado el hogar paterno; en muchos de los casos han consumado el matrimonio y ahora gozan de una vida en una casa propia. Empero, en otros casos, algunos hijos aún no se han marchado, y lo vemos en la localidad de Albuñol con el ejemplo de Isabel Ángel ${ }^{57}$, viuda de 85 años, que vive con su hija Petronila Carrillo de 55 años. No es difícil suponer que ambas podrían nutrirse de fórmulas flexibles que en numerosas ocasiones radican en el afecto y el cuidado mutuo ${ }^{58}$. Asimismo, otros parientes pueden haber permanecido o haber sido integrados posteriormente. Precisamente, en rangos de avanzada edad, no es extraño hallar hogares sin estructura compuestos por dos o más parientes, como es el caso de la viuda pobre de nombre María Granados, que a la edad de 66 años acogía en su hogar, situado en el Cortijo de Gálvez, distante media legua del pueblo de Albuñol, a su sobrina María Quesada de 30 años $^{59}$.

Gráfico 2. Ciclo de vida de mujeres cabeza de familia en una muestra de poblaciones en el sur de la intendencia de Granada (1752)

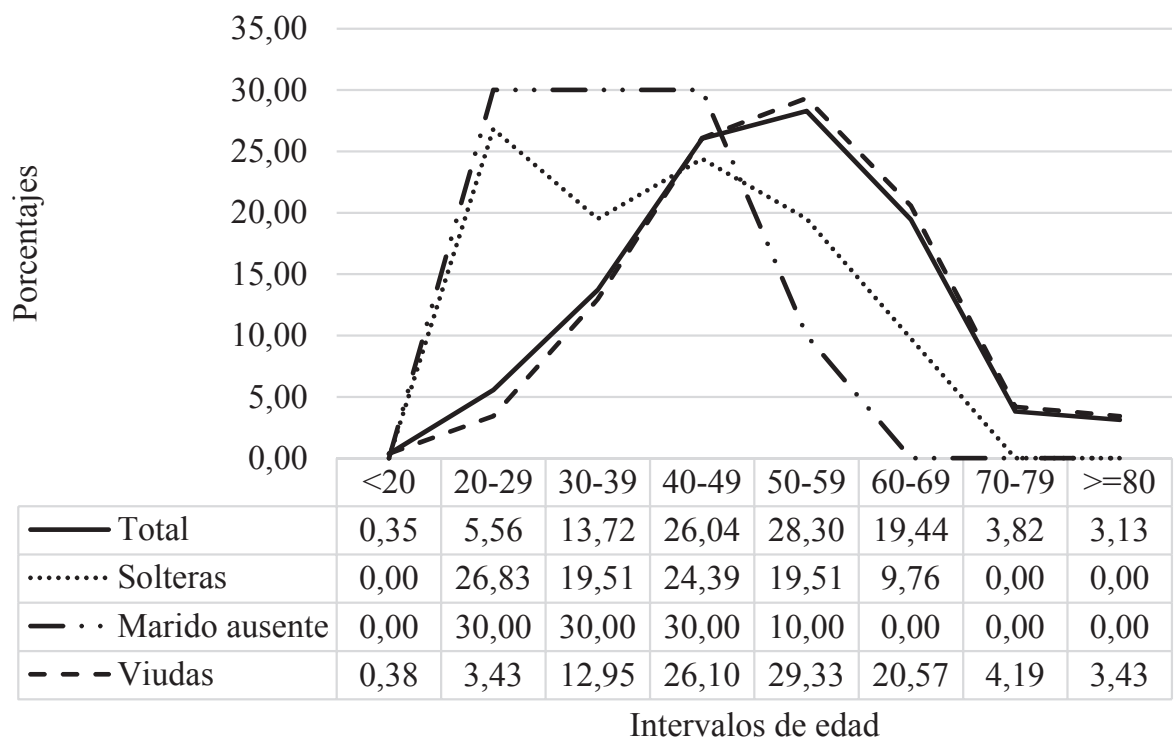

Fuente: Véase la nota 27. Elaboración propia.

57. AHPGr, Catastro de Ensenada, lib. 964, fol. 61v.

58. S. NAROTZKY (1991), 465.

59. AHPGr, Catastro de Ensenada, lib. 964, fol. 91v. 
Por último, conforme nos aproximamos cada vez más al estado de senectud, concretamente al sobrepasar la edad de 70 años, tan solo encontramos mujeres en estado de viudez. A pesar de que en todos los rangos de edad hallamos hogares con mujeres solas, la media de edad de estas jefas aumenta y se sitúa en 52,96 años. A medida que sus vidas se tornan hacia la vejez, la lucha por la supervivencia se vuelve más dura, por lo que han de tomar de múltiples estrategias que les permitan solventar las dificultades del día a día.

\section{EL ESPACIO SOCIOECONÓMICO DE LAS MUJERES QUE LIDERAN SU CASA}

Debemos tener en cuenta que el estado de viudez o de abandono no dejaba a las mujeres en total soledad o al margen de la sociedad. Precisamente, las relaciones sociales pasan por estrategias que nacen de los vínculos con otros familiares, ya sean tíos, sobrinos, primos o abuelos y que la estructura de los hogares complejos viene configurada por un haz de relaciones donde el matrimonio, aun siendo un elemento que define los comportamientos y la posición social de ambos $\operatorname{sexos}^{60}$, no puede analizarse como una componente inmóvil; al igual que cada individuo no permanece quieto e inmutable al paso del tiempo. Al contrario, tanto individuos como familias adquieren un determinado dinamismo evolucionando con el paso del tiempo ${ }^{61}$ porque, finalmente, todas las familias lideradas tanto por hombres como por mujeres sufren transformaciones como consecuencia de dichos factores.

Es cierto que existían dificultades y desventajas de cara al mundo público y la capacidad de maniobra de estas jefas de hogar para llevar una vida normal o simplemente encontrar un oficio que facilitase en la mayor medida su subsistencia estaba limitado. Sin embargo, ¿cuáles son sus estrategias de supervivencia y cómo cubrían sus necesidades básicas? Para responder a estas cuestiones debemos analizar las diferencias sociales en términos de desigualdad.

60. M. V. López-Cordón Cortezo (1998), 7.

61. En palabras del autor: "Dimensión evolutiva de las relaciones familiares". F. GARCíA GonZÁlez (2016), 20. 


\subsection{Economía de subsistencia: propiedad y desigualdad en la localidad de Albuñol}

Partiendo de un problema inicial que está estrechamente relacionado con la falta de información en el Catastro, lo cierto es que rastrear la ocupación laboral femenina remunerada se vuelve una tarea prácticamente imposible puesto que no ha quedado registrada en esta fuente de origen fiscal ${ }^{62}$. Precisamente, las poblaciones de la costa granadina contemplan una escasa documentación que se ha conservado con referencia a los libros de lo real o relaciones juradas de propiedad ${ }^{63}$. Tan solo algunas de estas localidades cuentan con esta valiosa fuente, entre ellas la localidad de Albuñol. Del mismo modo, los vecindarios seculares apenas dejan entrever alguna mínima referencia a oficios desempeñados por estas mujeres. Prueba de ello son los contados casos que obtenemos en nuestra muestra, de la que únicamente podemos señalar algunas labradoras y taberneras. El resto de los oficios queda oculto a ojos del historiador. Y esto en lo que atañe a mujeres al frente del hogar, porque si pretendemos indagar qué ocupaciones desarrollaban las mujeres casadas, el desafío es aún mayor. En contraposición, el universo ocupacional de los hombres descrito en la documentación es muy variado y está bien estructurado. Así disponemos de descripciones mejor detalladas en los siguientes oficios: maestro de molino de pan, estanquero de tabaco, soldado miliciano, cirujano o sacristán entre otros. Además, en algunos casos quedan registrados varios oficios que desempeña la misma persona, como es el caso de Antonio Pérez, de 40 años, habitante de Rubite y que ostenta las ocupaciones de tejedor de lienzos, basurero y jornalero. Está casado con Feliciana Casares, de 42 años, y juntos tienen 6 hijos $^{64}$.

Otro aspecto no menos importante que debemos remarcar es sin duda la distinta forma de denominación del concepto de pobreza, en este caso, de mujeres pobres o pobres de solemnidad. El número de mujeres pobres llegan en ocasiones a obtener la mitad de las jefas de familia, como son el caso de Motril y Albuñol. En contraste, los niveles de pobreza en hogares

62. Estudios realizados en Galicia avisan acerca de la gran dificultad para hallar información sobre el trabajo femenino a finales del Antiguo Régimen. S. M. Rial García (2009), 78.

63. Coincidimos con lo mencionado por Birriel Salcedo sobre la falta de documentación sobre propiedad en el Valle de Lecrín. M. a Birriel SAlcedo (2019), 75.

64. AHPGr, Catastro de Ensenada, lib. 1534, fol. 42. 
con jefatura masculina no son significativos, apenas llegan al $5 \%$. Pero ¿realmente, en qué grado de pobreza vivían estas mujeres? La respuesta no es fácil, sin embargo, tenemos pistas que nos pueden orientar. La media del capital de las mujeres cabezas de casa en Albuñol según el Catastro de Ensenada es de 363 reales, muy similar a la muestra analizada para el Valle de Lecrín ${ }^{65}$. El 77,77 \% de las mujeres al frente de sus hogares catalogadas como pobres posee alguna propiedad y mantienen una media de 78 reales por cabeza.

Para ilustrarnos mejor, veamos unos ejemplos, todos de la localidad de Albuñol. Ana Ruiz ${ }^{66}$ de 75 años, viuda sola y pobre que vive en una casa de cuarto bajo en la calle de la Iglesia y que además tiene en propiedad una casa cortijo, tres tierras de secano y una de regadío. En total puede ganar al año 232 reales de vellón. En otros casos, la precariedad puede ser más acuciante como el de María Martín de Ágreda ${ }^{67}$, viuda pobre de 52 años, que en 1752 vive con su hija María Alonso de 10 años. En ese año, y frente a la documentación de declaración de propiedad, María declara una casa en la calle Ballesteros por la que apenas saca 8 reales de arrendamiento y en 1757 lleva a cabo la compra de una viña en uso a Gabriela Morales de 65 años y viuda de Jacinto García. La viña tiene un censo de 400 reales de vellón, pero Gabriela advierte que la viña puede sacar más ganancias por su fruto. De nuevo, en 1757, Gabriela vende un pedazo de huerto a otra mujer, esta vez, a María Martín ${ }^{68}$, de 60 años, que estando casada en 1752 con Matías Fernández ${ }^{69}$, patrón matriculado de barco y con una barca en propiedad, un lustro después enviuda de este. Con estos ejemplos comprobamos que la denominación de pobreza no implica la absoluta ruina y fatalidad, especialmente si observamos las relaciones entre viudas y las estrategias que ponen en marcha para sacar adelante la economía de su hogar. Ahora bien, ¿cómo está constituido el patrimonio de estas mujeres?

65. Según los datos aportados por Marta Marín Sánchez, la media del capital fiscal de las mujeres que gobiernan su casa es de 356 reales. Véase M. ${ }^{a}$ Birriel Salcedo (2019), 67.

66. AHPGr, Catastro de Ensenada, lib. 964, fol. 33r.

67. Un matiz importante que aparece en este protocolo notarial es el nombre del difunto marido que fue de María Martín, es decir, Esteban Alonso. APGR, Escribanía de Benito García Calleja, leg. AB-42, fol. 4r. Venta real, María Martín de Ágreda contra Gabriela Morales 9 de enero de 1757.

68. APGR, Escribanía de Benito García Calleja, leg. AB-42, fol. 10r. Venta real, María Martín contra Gabriela Morales 12 de noviembre de 1757.

69. AHPGr, Catastro de Ensenada, lib. 964, fol. 69v. 
Tabla 3. Nivel de riqueza de los hogares encabezados por hombres y mujeres en la localidad de Albuñol (1752)

\begin{tabular}{|c|c|c|c|c|c|c|c|}
\hline & \multicolumn{2}{|c|}{ Bienes inmuebles } & \multicolumn{2}{|c|}{ Cabezas de ganado } & \multicolumn{3}{|c|}{ Tierras en propiedad } \\
\cline { 2 - 8 } & Total & $\begin{array}{c}\text { Reales de } \\
\text { vellón }\end{array}$ & Total & $\begin{array}{c}\text { Reales de } \\
\text { vellón }\end{array}$ & Total & $\begin{array}{c}\text { Extensión } \\
\text { (celemines) }\end{array}$ & $\begin{array}{c}\text { Reales de } \\
\text { vellón }\end{array}$ \\
\hline \multirow{4}{*}{ Mujeres } & 65 & 2967 & 848 & $\begin{array}{c}3526 \text { y } 11 \\
\text { maravedís }\end{array}$ & 220 & 3107,50 & $\begin{array}{c}14305 \text { y } 23 \\
\text { maravedís }\end{array}$ \\
\cline { 2 - 8 } & $\mathbf{A}$ & $\mathbf{D}$ & $\mathbf{A}$ & $\mathbf{D}$ & $\mathbf{A}$ & $\mathbf{C}$ & $\mathbf{D}$ \\
\cline { 2 - 8 } & 70,88 & 46 y 31 & 31,64 & $\begin{array}{c}141 \text { y } 6 \\
\text { maravedís }\end{array}$ & 65,82 & 24,17 & $\begin{array}{c}275 \text { y } 11 \\
\text { maravedís }\end{array}$ \\
\hline \multirow{4}{*}{ Hombres } & 182 & 7106 & 1985 & $\begin{array}{c}8260 \text { y } 29 \\
\text { maravedís }\end{array}$ & 639 & 9748,75 & $\begin{array}{c}45024 \text { y } 30 \\
\text { maravedís }\end{array}$ \\
\cline { 2 - 8 } & $\mathbf{B}$ & $\mathbf{E}$ & $\mathbf{B}$ & $\mathbf{E}$ & $\mathbf{B}$ & $\mathbf{C}$ & E \\
\cline { 2 - 8 } & 84,33 & $\begin{array}{c}51 \text { y } 14 \\
\text { maravedís }\end{array}$ & 59,03 & $\begin{array}{c}87 \text { y } 18 \\
\text { maravedís }\end{array}$ & 84,33 & 75,82 & $\begin{array}{c}321 \text { y } 16 \\
\text { maravedís }\end{array}$ \\
\hline
\end{tabular}

Fuente: Catastro de Ensenada. Documentación de Hacienda. Respuestas particulares de Albuñol Nota $^{70}$ : A: Porcentaje de propietarias sobre el total de jefas del hogar. B: Porcentaje de propietarios sobre el total de jefes del hogar. C: Porcentaje de tierra catastrada. D: Valor medio en reales de vellón por cada jefa del hogar sobre el total de propietarias. E: Valor medio en reales de vellón por cada jefe del hogar sobre el total de propietarios.

Si nos fijamos en la Tabla 3 (caso de Albuñol) se pueden apreciar diferencias entre ambos sexos. Por un lado, el acceso a la tierra para los hombres es mayor, con un $84,33 \%$, mientras que para las mujeres es de un $65,82 \%$. De estas, tan solo un $5,76 \%$ son labradoras o tienen un patrimonio pudiente. Algo similar ocurre con los inmuebles en propiedad y en el caso del ganado la brecha aproximadamente alcanza el $30 \%$ más para los hombres. Por otro lado, el $27,84 \%$ de las mujeres cabeza de familia de esta localidad no posee bienes inmuebles y el $34,17 \%$ no tiene tierras. Según su estado civil, el 89,06 \% de todas las mujeres que tienen

70. Para la elaboración de dicha tabla nos hemos basado en el modelo elaborado por Rial García en el Cuadro 7 sobre "porcentajes de tierra y ganado controlado por jefas del hogar en cada una de las parroquias costeras". Véase S. M. Rial García (2005), 94.

71. En zonas de la montaña leonesa, la tenencia de tierras por parte de las mujeres al frente del hogar es bastante bajo, los datos arrojan un 12,10\% de hogares encabezados por una mujer. M. ${ }^{a}$ J. Pérez Álvarez (2013), 19. 
propiedades son viudas, frente al mínimo porcentaje de mujeres con marido ausente $(4,68)$ y solteras $(3,12)$.

Según las respuestas generales del Catastro $^{72}$, los montes bajos que rodeaban la población servían para la siembra de cebada, maíz, trigo y garbanzos y el número de jornaleros alcanza la centena y no sólo se dedican a las labores del campo, sino que además se emplean en el manejo de tirar de la red o copo $^{73}$ y demás faenas pesqueras. A pesar de que ahora mismo no tenemos a nuestra disposición más información, debemos preguntarnos si una gran parte de las mujeres que habitaban en Albuñol a finales del Antiguo Régimen no participaría de las labores agrícolas y en el desarrollo de diversas actividades del mar. Precisamente, cuando el ganado asnal predomina en la mayoría de los hogares gobernados por mujeres, puesto que se trata de un animal básico de carga y transporte lo que deja entrever el desempeño de actividades que traspasan la esfera doméstica. Asimismo, no sobresale el ganado ovino, pero si el caprino por cuyo esquilmo se pueden ganar hasta 4 reales por cabeza, como es el caso de la viuda Victoria Barranco $^{74}$, de 40 años, con sus 45 cabezas de ganado caprino o la labradora viuda de 60 años llamada Clemencia Valdés ${ }^{75}$, con sus 400 cabezas.

Es evidente que la balanza patrimonial se halla descompensada, no obstante, hay que precisar dos detalles importantes. En primer lugar, una parte de la propiedad que pertenece a los hombres casados corresponde a sus esposas. De ahí que en la mayoría de los casos sea prácticamente imposible saber qué pertenece a quién, ya que dichos bienes quedan diluidos en el total del patrimonio familiar. Esta circunstancia no se trata de algo aislado, sino más bien de una característica estructural propia de una sociedad prioritariamente patriarcal donde los bienes dotales aportados por la esposa al matrimonio pasan a estar bajo el dominio del marido ${ }^{76}$. Dicha realidad se puede observar en la documentación del Catastro de Ensenada donde la mayor parte de las propiedades es controlada por los hombres.

De hecho, la búsqueda del registro de propiedades relativas a las mujeres con marido ausente se vuelve una tarea extremadamente complicada

72. Ach. R. Ch. Gr., Catastro de Ensenada.

73. "2. m. Bolsa o saco de red con que terminan varias artes de pesca". Real Academia Española, Diccionario de la lengua española, 23.a ed., [versión 23.3 en línea].

74. AHPGr, Catastro de Ensenada, lib. 964, fol. 193r.

75. AHPGr, Catastro de Ensenada, lib. 964, fol. 335r.

76. Para conocer el acceso patrimonial por mujeres al frente de sus hogares en zonas marítimas de Galicia, véase S. M. Rial García (2005), 93. 
ya que, en numerosas ocasiones, aunque el vecindario secular registre a estas mujeres como cabezas de familia, el propietario es el marido ${ }^{77}$. Y como apuntábamos desde un principio, en esos casos, el nombre del esposo no suele aparecer en el propio vecindario. En este sentido, Albuñol es una excepción y así lo atestigua la declaración de bienes de Juan García ${ }^{78}$, ausente, matriculado en los navíos y con una casa en el barrio de la Iglesia y un viñedo en propiedad. Está casado con Quiteria Ruiz, de edad 40 años, y tiene tres hijos de entre 3 y 13 años. Y aunque no lo refleje el Catastro, podemos asumir con cierta ligereza que Quiteria Ruiz se haría cargo del cuidado de la casa y de la tierra.

En segundo lugar, si contrastamos los niveles gananciales en reales de vellón de ambos sexos (Tabla 3), las distancias parecen acortarse. Incluso queda patente el valor superior en cuanto a las cabezas de ganado, donde en esta población, las mujeres jefas de hogar obtienen mayores ganancias alcanzando los 141 reales de vellón de media. En un principio, esta circunstancia se debe al hecho de que en el momento en que la mujer asume todas las responsabilidades del hogar, también obtiene, en parte, cierta flexibilidad ${ }^{79}$ a la hora de gestionar sus propiedades y acceder más fácilmente a la compra y venta de tierras o inmuebles.

Lo vemos mejor con el ejemplo de la labradora viuda Juana Rodríguez $^{80}$, de edad 42 años, quien vive con tres hijos y es viuda de Francisco López, que según el Catastro de Ensenada en 1752 posee dos casas, numerosas tierras de regadío y secano y 6 cabezas de ganado. En 1754 compra cuatro fanegas de tierra de secano a los herederos de María Moreno, Manuel Moreno y Miguel Rodríguez. Un año más tarde ${ }^{81}$ vende su casa, que tiene ubicada en el barrio de la Iglesia, a José de Acosta vecino de la misma localidad. La casa tiene dos censos (cuando hace 3 años, según el Catastro, no los tenía) que paga Juana Rodríguez a la población. Situación

77. Se trata de una realidad que también se daba en pueblos del reino de Jaén, véase R. Tovar Pulido (2017), 201.

78. AHPGr. Catastro de Ensenada, lib. 965, fol. 182r.

79. En el estado de Ceará en Brasil, la ausencia del marido y la viudez permitían cierta libertad a la hora de administrar los bienes familiares por parte de las mujeres cabeza de familia, véase A. P. Santiago De Freitas y A. C. Farias De Alencar (2017), 94.

80. APGR, Escribanía de Benito García Calleja, leg. AB-42, fol. 97r. Venta real Juana Rodríguez contra Manuel Moreno y Miguel Rodríguez, 26 de septiembre de 1754.

81. APGR, Escribanía de Benito García Calleja, leg. AB-42, fol. 54r. Venta real José de Acosta contra Juana Rodríguez, 15 de Agosto de 1755. 
parecida es a la que se enfrenta Isabel Morales ${ }^{82}$, viuda de Esteban Valdés y vecina de Albuñol, que, en 1752, a la edad de 56 años, vive con su hijo Antonio Valdés, de 32 años e impedido por falta de razón y su hija María Valdés, de 24 años. Según la relación de propiedad de ese mismo año, este hogar declaraba entre tierras de secano y regadío, así como una casa, aproximadamente 297 reales $^{83}$. Dos años después, Isabel venderá en venta real un pedazo de huerto de medio cuartillo a Matías Fernández, vecino de la misma villa. Sin embargo, ahora se ha sumado un censo a favor de la población y contra Isabel de 190 reales que ella misma confiesa haber recibido de otro comprador.

En ocasiones, a través de la documentación notarial, no solo completamos información, sino que descubrimos detalles en el trascurso del tiempo. Este es el caso de Margarita Martín ${ }^{84}$ que en los datos arrojados por el Catastro queda registrada como viuda pobre, de 42 años, que no deja registro alguno de propiedad, por lo que no aparece entre las declarantes de las relaciones juradas, y con dos hijos y una hija, todos ellos de entre 10 y 18 años, a su cargo. Pues bien, en 1758, la susodicha compra un corral cercado a Manuel Sánchez de Ayala ${ }^{85}$. También, el ejemplo de Bárbara Fernánde $z^{86}$ que, en 1752, estaba casada con don Toribio López, de 55 años labrador y estanquero de tabaco y que en cambio, en 1756 queda registrada como viuda del mencionado en un protocolo notarial donde ella misma otorga un poder general a un tal don Francisco Gutiérrez para que la defienda en todos los pleitos.

Por último, es de vital importancia revisar las conexiones entre núcleos de población, como es el caso de doña Petronila de Victoria y Chafino ${ }^{87}$, de edad 23 años y soltera, vecina de Motril, la cual afirma que gobierna su persona y no está sujeta a patria potestad alguna. En 1754, esta mujer declara en la villa de Albuñol vender un pedazo de tierra de secano de 8 fanegas a Francisco Bueno, labrador de 31 años y vecino de Rubite. Tam-

82. APGR, Escribanía de Benito García Calleja, leg. AB-42, fol. 151r. Venta real Matias Fernández contra Isabel Morales, 5 de diciembre de 1754.

83. AHPGr, Catastro de Ensenada, lib. 964, fol. 300r.

84. AHPGr, Catastro de Ensenada, lib. 964, fol. 80r.

85. APGR, Escribanía de Benito García Calleja, leg. AB-42, fol. 17r. Venta real Margarita Martín contra Manuel Sánchez de Ayala, marzo de 1758.

86. APGR, Escribanía de Benito García Calleja, leg. AB-42. Poder general, Doña Bárbara Fernández contra Francisco Gutiérrez, 16 de junio de 1756.

87. APGR, Escribanía de Benito García Calleja, leg. AB-42, fol. 96r. Venta real, Francisco Bueno contra Doña Petronila de Victoria y Chafino, septiembre de 1754. 
bién, en marzo de 1752, Petronila vende un molino harinero de una parada, cubo, alberca, acequia y demás pertrechos, así como un sotillo y un huerto a Juan González, labrador de 60 años y vecino de Rubite ${ }^{88}$. Asegura en dicha venta no poseer ningún tutor que la ampare y que estos bienes los ha heredado de sus difuntos padres. Aun no sabiéndolo con certeza, doña Petronila tal vez se viese forzada a despojarse de sus propiedades para solventar alguna deuda ${ }^{89}$, en este caso queda registrado que tiene en su contra varios censos y memorias que paga a la población. Con todo, esta joven parece permanecer en su casa tras el fallecimiento de sus padres y tomar las riendas del hogar sin acudir a la fórmula del auspicio por parte de algún familiar ${ }^{90}$.

\section{CONCLUSIONES}

La dificultad de abordar el campo de análisis sobre el ámbito femenino reside en que la historia de las mujeres ha ocupado un segundo plano en las preferencias del análisis histórico del periodo moderno. A pesar de ello, poco a poco, la producción científica en torno a esta problemática está contemplando nuevos caminos de investigación que se aproximan a temáticas con otra proyección social. Bajo el paraguas de estas novedosas líneas de investigación, la metodología empleada en este trabajo ha decidido usar la conexión nominativa que implica el cruce y la comparación de fuentes. Se apuesta por dar un giro a dichas fuentes de documentación $\mathrm{y}$ volverlas a analizar desde otras perspectivas y enfoques para reivindicar que las mujeres viven en un contexto determinado y se encuentran insertas en un sistema social donde las relaciones con otros individuos y el espacio en el que se desarrollan sus actividades nos darán las claves para analizar la complejidad social en su conjunto.

A su vez, el examen anterior nos confirma tres aspectos destacables. El primero, tiene que ver con el análisis de la tipología del hogar en esta muestra de poblaciones, donde se pone de manifiesto la relevancia del estado de viudez en las jefaturas femeninas frente a las masculinas. Queda comprobado que no existen grandes diferencias en torno a los porcentajes de hogares encabezados por mujeres viudas, como veíamos en el caso

88. APGR, Escribanía de Benito García Calleja, leg. AB-42, fol. 89r. Venta real, Juan González contra Doña Petronila de Victoria y Chafino, marzo de 1752.

89. C. Ramos Cobano (2010), 440.

90. F. García González y D. Maldonado Cid (2019), 144. 
de Jaén o el número de jefas de hogar que se asemeja a los reflejados en zonas del Valle de Lecrín y la España centro-meridional. De igual forma, con respecto a las jefaturas femeninas, el modelo nuclear está caracterizado por ser liderado, en su mayoría, por mujeres viudas, y en esto no se dan grandes diferencias entre las entidades poblacionales de la muestra. Por ello, debemos ir más allá y analizar las dinámicas sociales por cuanto que la forma por la que mutan el estado civil y los niveles de riqueza de estas mujeres con el paso del tiempo se ve reflejada en los protocolos notariales. El segundo aspecto trata de la compleja red de relaciones que se desarrollan en el seno de las familias, especialmente cuando se integran otros parientes o allegados, ya fuesen las causas económicas, de parentesco, de profesión o, incluso, de abandono. Por último, la denominación de pobre o pobre de solemnidad no quiere decir que estas mujeres se encuentren en un contexto de desamparo y absoluto abandono, sino que se ponen en marcha determinadas estrategias de supervivencia como las expresadas a través de las compraventas donde se percibe la manera en la que trascienden los intercambios y las relaciones entre estas féminas.

En definitiva, este trabajo pretende luchar contra el vacío bibliográfico en torno al estudio de las jefaturas femeninas, de ahí que nuestro interés abogue más por abandonar ciertas pautas basadas en la idealización de una historia en la que ya está todo estudiado, abordando así, otros temas que amplíen el conocimiento y logren, al menos, poner en duda esta idea anquilosada de la historia como algo cerrado. No obstante, el reto de visibilizar la vida de las mujeres durante el periodo moderno está aún por lograr su cometido.

\section{BIBLIOGRAFÍA}

Birriel Salcedo, Margarita M. ${ }^{a}$ (2005), "Jefaturas de hogar femeninas en la ciudad de Granada (1752). I: Caracterización demográfica del hogar”, en A. L. Cortés Peña, M. L. López-Guadalupe Muñoz y F. Sánchez-Montes González (eds.), Estudios en homenaje al profesor José Szmolka Clares, Universidad, Granada, pp. 591-604.

- (2019), "Ellas gobiernan la casa: Jefaturas de hogar femeninas en el Valle de Lecrín (s. XVIII)", Centro de Estudios Históricos de Granada y su Reino, 31 , pp. $57-82$.

Botelho, Lynn (2013), "Old Women in Early Modern Europe: Age as an Analytical Category", en A. M. Poska, J. Couchman y K. A. Mciver (eds.), The Ashgate Research Companion to Women and Gender in Early Modern Europe, Routledge, Nueva York, pp. 297-315. 
Camarero Bullón, Concepción; Aguilar Cuesta, Ángel y García Juan, Laura (2018), "El Vecindario y el Censo de Ensenada: el final de una época y el inicio de otra en los recuentos poblacionales", CT: Catastro, 93, pp. 31-63.

CAsey, James y Vincent, Bernard (1987), "Casa y familia en la Granada del Antiguo Régimen”, en P. VILAR, (ed.), La familia en la España mediterránea (Siglos XV-XIX), Crítica, Barcelona, pp. 172-211.

Castellano, Juan Luis (2012), El Siglo de las Luces. Agricultura y sociedad motrileña, Ingenio, Biblioteca de Motril, Motril.

Cruz CÁrdenas, Sara (2019), "Jefaturas de hogar femeninas en el Albaicín de Granada (1752)", Revista del Centro de Estudios Históricos de Granada y su Reino, 31, pp. 41-56.

De La Pascua Sánchez, M. a José (2016), “Vivir en soledad, vivir en compañía: las mujeres y el mundo familiar en el siglo XVIII hispánico", en M. R. García Hurtado (ed.), El siglo XVIII en femenino, Síntesis, Madrid, pp. 151-190.

- (2016), "A la sombra de hombres ausentes: mujeres malcasadas en el mundo hispánico del setecientos", Studia Historica. Edad Moderna, 39, 237-285.

Del Cerro Bohórquez, M. ${ }^{a}$ Paz (2004), Mujer, herencia y matrimonio en la sociedad rural gaditana del Antiguo Régimen, Universidad, Cádiz.

Edvinsson, Sören y Broström, Göran (2012), "Old age, health, and social inequality: Exploring the social patterns of mortality in $19^{\text {th }}$ century northern Sweden", Demographic Research, 26, 23, pp. 633-660.

Fernández García, M. a Ángeles (1982), “La evolución demográfica de Almuñécar en el siglo XVIII", Chronica Nova, 13, pp. 143-156.

- (1985), "El partido y señorío de Torvizcón en el siglo XVIII”, Chronica Nova, 14, pp. 123-145.

García GonzÁlez, Francisco (2011), "Las estructuras familiares y su relación con los recursos humanos y económicos", en F. Chacón JimÉnez y J. Bestard Comas (coords.), Familias: historia de la sociedad española (del final de la Edad Media a nuestros días), Cátedra, Madrid, pp. 159-254.

- (2015), "Investigar la soledad. Mujeres solas, casa y trayectorias sociales en la Castilla rural a finales del Antiguo Régimen Francisco", Obradoiro de Historia Moderna, 24, pp. 141-169.

- (2016), "Presentación", Studia Histórica. Historia Moderna, 38, 2, pp. 19-26.

- (2017), "Mujeres al frente de sus hogares. Soledad y mundo rural en la España interior del Antiguo Régimen," Revista de Historiografía, 26, pp. 19-46.

García González, Francisco y Maldonado Cid, Daniel (2019), “Bajo el mismo techo. Los hogares en Andalucía a finales del Antiguo Régimen”, Chronica Nova, 45, pp. 131-163.

Gehrmann, Rolf (2017), "Mujeres cabeza de familia en Alemania y Francia evidencia de los censos de 1846," Revista de Historiografia, 26, pp. 167-186. 
Girón Pascual, Rafael M. (octubre de 2015), "Puertos sin puerto: El comercio en las "playas" del reino de Granada (siglos XVI-XVII)", e-Spania. Revue interdisciplinaire d'études hispaniques médiévales et modernes, URL: http:// journals.openedition.org/e-spania/25014

Gómez Martín, Miguel (1997), "Dote y herencia en la Vega de Granada. Alfacar en el siglo XVIII”, en M. ${ }^{\text {a }}$ V. LÓPEZ CORDÓN y M. CARBONELL (eds.), Historia de la mujer e historia del matrimonio, Universidad, Murcia, pp. 183-190.

Hernández Bermejo, M. a Ángeles (2012), “El mundo de las viudas en una zona rural de la Extremadura del siglo XVIII”, en M. J. Pérez Álvarez y L. M. Rubio Pérez (eds.), Campo y campesinos en la España Moderna. Culturas políticas en el mundo hispano, Fundación Española de Historia Moderna, Madrid, pp. 1235-1245.

LóPez-Cordón, M. ${ }^{a}$ Victoria (1998), "Familia, sexo y género en la España Moderna”, Studia Histórica. Historia Moderna, 18, pp. 105-134.

Marcos Martín, Alberto (2000), España en los siglos XVI, XVII, XVIII. Economía y sociedad, Crítica, Barcelona.

Marín SÁnchez, Marta, "Familia y sociedad: estrategias familiares en la población de Pinos del Valle (1752)", en M. ' J. Ortega Chinchilla, M. Marín Sánchez y M. M. ${ }^{a}$ Birriel Salcedo (eds.), El Pinar en el Catastro de Ensenada (en prensa).

Moring, Beatrice y Wall, Richard (2017), Widows in European economy and society 1600-1920, The Boydell Press, Woodbridge.

NARotzky, Susana (1991), "La renta del afecto: ideología y reproducción social en el cuidado de los viejos", en J. Prat; U. Martínez; J. Contreras y I. Moreno (eds.), Antropología de los Pueblos de España, Taurus, Madrid, pp. 464-474.

Nausia Pimoulier, Amaia (2006), "Las viudas y las segundas nupcias en la Europa moderna: últimas aportaciones", Memoria y Civilización, 9, pp. 233-260.

- (2011), Entre el luto y la supervivencia. Viudas y viudedad en la Navarra Moderna (Siglos XVI y XVII). Tesis doctoral, Universidad de Navarra.

Pérez Álvarez, M. ${ }^{a}$ José (2013), "Mujeres y jefatura del hogar en el mundo rural leonés durante la Edad Moderna”, Cuadernos de Historia Moderna, 38, pp. 15-39.

Porras Arboledas, Pedro Andrés (2006), "La vida cotidiana en el Motril de la época moderna a través de los Autos de Buen Gobierno", Cuadernos de Historia del Derecho, 12, pp. 151 - 177.

Ramos Cobano, Cristina (2010), "De ocupación, no sólo sus labores: la mujer y la propiedad de la tierra en la Andalucía del siglo XVIII", en Família pagesa i economía rural. VII Congrés sobre sistemes agraris, organització social i poder local, Institut d'Estudis Ilerdencs, Lleida, pp. 425-443.

Rey Castelao, Ofelia (2006), "Les femmes «seules» du nord-ouest de l'Espagne. trajectoires féminines dans un territoire d'emigration 1700-1860", Annales de démographie historique, 2, 112, pp. 105-133. 
- (2009), "La historia de las mujeres en Galicia. Un estado de la cuestión (19882008)", Minius, 17, pp. 191-234.

Rial García, Serrana Mercedes (2001), "Las mujeres y el patrimonio en dos comunidades costeras de las Rías Baixas”, Obradoiro de Historia Moderna, 10, pp. 89-120.

- (2005), Las mujeres de las comunidades maritimas de Galicia durante la época moderna. Una biografía colectiva, Ayuntamiento, Alcalá de Henares.

- (2009), "Trabajo femenino y economía de subsistencia: el ejemplo de la Galicia moderna", Manuscrits, 27, pp. 77-99.

Rial García, Serrana y Rey Castelao, Ofelia (2008), "Las viudas de Galicia a fines del Antiguo Régimen”, Chronica Nova, 4, pp. 91-122.

Rodríguez Alemán, M. a Isabel (2008), "Opciones matrimoniales de la mujer viuda en Málaga (1564-1700)”, Chronica Nova, 34, pp. 123-157.

Rueda Solano, Jesús (2013), "Entre la omisión y el protagonismo. La mujer en Alhaurín el Grande según las Respuestas Particulares del Catastro de Ensenada (1752)", en P. Pezzi Cristóbal (coord.), Historia(s) de mujeres en homenaje a M. ${ }^{a}$ Teresa López Beltrán, vol. II, Perséfone: Ediciones Electrónicas de la AEHM/UMA, Málaga, pp. 188-228.

SÁnchez-Montes GonzÁlez, Francisco (2019), "La familia en el reino de Granada en la Edad Moderna”, Chronica Nova, 45, pp. 131-163.

Santiago De Freitas, Antônio de Pádua y Farias De Alencar, Ana Cecilia (2017), "«Dona», viúva e «cabeça de casal»: mulheres administradoras de bens nos sertöes de Quixeramobil - Ceará, Brasil (século XVIII)", Revista de Historiografía, 26, pp. 19-46.

Sanz De La Higuera, Francisco José (2006), “Casada o viuda? El abandono del hogar en el Burgos de mediados del siglo XVIII", Huarte de San Juan. Geografía e Historia, 13, pp. 211-242.

Sanz SAmpelayo, Juan (1978), "Importancia de las nuevas nupcias contraídas por viudos en los ciclos demográficos antiguos: características con que se presentan en la Granada del siglo XVIII", en Actas del I Congreso de Historia de Andalucía. Andalucía Moderna (siglo XVIII), t. II, Monte de Piedad y Caja de Ahorros, Córdoba, pp. 253-263.

Sorroche, M. Ángel. (2014), "La Sierra de Lújar (Granada). Poblamiento y arquitectura tradicional como valores patrimoniales", Revista del Centro de Estudios Históricos de Granada y su Reino, 26, pp. 289-314.

Tovar Pulido, Raquel (2014-2015), "Entre la marginalidad y la soledad: las viudas de Vilches (Jaén) a mediados del siglo XVIII", Norba. Revista de Historia, 27-28, pp. 405-420.

- (2017), "La riqueza patrimonial de las familias de las viudas jiennenses en el siglo XVIII", Cuadernos de Historia Moderna, 42 (1), pp. 195-220.

Velasco Merino, Eduardo (2014), "La senectud en el mundo rural: la dependencia del «viejo» en la localidad zamorana de Fermoselle entre 1750-1825", Tiempos Modernos, vol. 8, 29. 